\title{
Provetá: a Assembleia, em um lugar de Deus
}

\author{
Nelson Cortes Pacheco Junior ${ }^{7}$ \\ Antonio Bernardes \\ Felipe Rodrigues de Almeida Maia ${ }^{3}$
}

\begin{abstract}
Resumo: É trivial ouvirmos, nas ruas das cidades, as pessoas conversando sobre aqueles que são crentes. A denominação de crente no Brasil possui um caráter genérico e está associada aos sujeitos praticantes das religióes cristãs protestantes. Em sentido conotativo, o crente seria aquele que crê, mas, no sentido denotativo, são os cristãos protestantes. Desse modo, este artigo busca para além da discussão acerca do sagrado e do profano na Vila de Provetá, localizada na Ilha Grande no município de Angra dos Reis-Rio de Janeiro, abordar como a denominação Assembleia de Deus se estabeleceu por lá, como ela consolidou suas ideologias e práticas religiosas vinculadas ao cristianismo protestante e, sobretudo, como ressignificou a Vila como um lugar sagrado, polarizando os mais diferentes aspectos sociais.
\end{abstract}

Palavras-chave: Provetá; Lugar; Ser assembleiano; Outro.

\section{Provetá: the Assembly, in a God's place}

\begin{abstract}
On the streets of Brazilian cities, it is common to hear people talking about those who are 'believers'. The word 'believer' has a generic meaning in Brazil and is associated with practitioners of Protestant Christian religions. In a connotative sense, the 'believers' would be those who believe, but in a denotative sense, they are Protestant Christians. Thus, this essay is not just about exploring the interfaces between the sacred and the profane, but also investigating how 'Assembleia de Deus' is established in Ilha Grande (Angra dos Reis city, Rio de Janeiro), how it has consolidated its ideologies and religious practices, linked to Protestant Christianity, and, above all, how it redefined the village as a sacred place, polarizing the most different social aspects.
\end{abstract}

Keywords: Provetá; place; being an assembly member; other.

\footnotetext{
1 Mestre em Geografia pela Universidade Federal Fluminense (UFF). Pesquisador do CRELIG (UFRRJ), do NEPEC em Rede (UERJ) e do Geo.Con (UFF). ORCID iD: https://orcid.org/0000-0002-2056-372X; E-mail: ncpj35@gmail.com

2 Pós Doutor em Geografia pela Universidade Estadual Paulista (UNESP - Presidente Prudente). Docente do Programa de Pós-graduação em Ciências Humanas e Sociais Aplicadas (UNICAMP), do Programa de Pós-graduaçáo em Geografia (UFSCar - SP) e da Graduação em Geografia (UFF - Angra dos Reis - RJ). Pesquisador do NEPEC em Rede (UERJ), do LAGERR (UNICAMP - Limeira) e do Geo. Con (UFF). ORCID iD: https://orcid.org/0000-0002-4996-7031; E-mail: antoniobernardes1981@gmail.com

3 Graduado em Geografia pela Universidade Federal Fluminense (UFF - Angra dos Reis - RJ). E-mail: ncpj35@gmail.com
} 


\section{Prelúdio}

É trivial ouvirmos, nas ruas das cidades brasileiras, as pessoas conversando acerca daqueles que são crentes. A denominação de crente no Brasil possui um caráter genérico e está associada aos sujeitos praticantes das religiốes cristãs protestantes. Em sentido estritamente conotativo, o crente seria aquele que crê, mas, no sentido denotativo, são os cristãos protestantes.

Seja em uma breve caminhada pelas ruas dos bairros periféricos das grandes metrópoles brasileiras ou mesmo nos vagóes de trem e nos ônibus urbanos, não é difícil encontrarmos os crentes em missóes de evangelização. Além da profusão de palavras em alto e bom tom, em meio público, eles são identificados por um tipo específico de vestimenta: terno e gravata para os homens e vestido longo para as mulheres.

As vestimentas utilizadas pelos cristãos protestantes no Brasil são uma das suas formas de identificação e estranhamento. Ora, mas essas vestimentas não possuem nada de estranho. Sim, realmente! Mas temos que levar em conta que a emergência do protestantismo no Brasil ocorreu e ocorre pelas periferias metropolitanas. Por um lado, tais vestimentas podem denotar seriedade, ortodoxia e polidez, visto que elas são uma forma de os crentes respeitarem o culto religioso ou as açôes missionárias. Por outro lado, estar trajado com roupa social é fora do padrão para boa parte dos sujeitos que vivem nas periferias das metrópoles brasileiras, o que pode ocasionar certo estranhamento.

Obviamente, essas simbologias populares não traduzem as especificidades que cada segmento do cristianismo protestante possui. Por exemplo, ainda em linhas gerais, temos os pentecostais e neopentecostais. Os protestantes pentecostais são considerados mais ortodoxos e seguem as indicaçóes bíblicas. No Brasil, a Assembleia de Deus, a Deus é amor e a Congregação Cristã do Brasil são algumas da principias denominaçôes. Já os neopentecostais são considerados heterodoxos e acreditam em princípios pós-bíblicos, na cura, na realização de profecias e em batalhas espirituais. Dentre as principais denominaçóes temos: a Igreja Universal do Reino de Deus, a Igreja Internacional da Graça e a Renascer em Cristo.

Em uma visão apressada, poderíamos considerar que, para os protestantes, haveria duas referências toponímicas básicas: a igreja como o local sagrado, que pode ser ressignificada como um lugar devido ao contato com Deus; e como o espaço público, dentre eles, a rua, as praças, os vagóes de trem e de metrô, os ônibus etc. como locais profanos para evangelizaçáo. Então há um dentro e um fora. A igreja como o de dentro, o lugar sagrado, e o espaço público como $o$ de fora, o local profano. Mas, sobretudo, o dentro e o fora estáo vinculados aos sujeitos com os quais os crentes se relacionam. Há aqueles que são de dentro, os irmãos - denominação atribuída pelos crentes aos praticantes do protestantismo neopentecostal - e os de fora, Outros, não-irmãos, como aponta Birman (2006).

De início, expusemos o que há de mais comum e genérico acerca dos crentes, ou seja, algumas simbologias e o seu perambular por missóes de evangelização, em locais profanos nas periferias das metrópoles brasileiras, mas nem tudo é assim. Poderíamos mencionar as missóes de evangelização internacional na África, com trabalhos filantrópicos e sincretismos religiosos entre os cristãos protestantes e os baloberos, morus e djambakus (PACHECO JR., 2020). Ou, 
ainda, um caso muito especial, a organização religiosa, política, econômica e cultural de uma comunidade em torno de uma denominação evangélica. Referimo-nos à Vila de Provetá, localizada na Ilha Grande, no município de Angra dos Reis-RJ.

Na Vila de Provetá, a denominação Assembleia de Deus mantém, há algumas décadas, uma espécie de poder centralizador das açôes que norteiam a vivência das pessoas. Lá, os de dentro e os de fora possuem outro aspecto. Os de dentro são os membros da comunidade que se tornaram adeptos do protestantismo e os de fora são os forasteiros, principalmente, turistas que não são da comunidade e que, em muitos casos, não são evangélicos e os membros da comunidade que não são adeptos à denominação. $\mathrm{O}$ espaço público por lá não é profano, como nos casos que mencionamos, ele é sagrado. Isso ocorre porque, nessa Vila, o espaço sagrado é estendido, já que a Assembleia de Deus centraliza as açóes e os estende. Então, onde estaria o espaço profano?

Mais do que a discussão acerca do sagrado e do profano na Vila de Provetá, discutiremos, neste texto, como a denominaçáo Assembleia de Deus se estabeleceu por lá, como ela consolidou suas ideologias e práticas religiosas e, sobretudo, como ressignificou a Vila como um lugar sagrado, polarizando os mais diferentes aspectos sociais. Assim, partimos da perspectiva fenomenológico-existencial, segundo a qual o lugar não é algo aleatório existente no espaço, pelo contrário, para que ocorra a abertura do ser e os acontecimentos essenciais do cotidiano, é necessário que haja um lugar, pois é por ele que "nos identificamos, ou nos lembramos, constituindo assim a base de nossa existência no mundo" (MARANDOLA JR., 2012, p. 228). É nele que o ser-aí que somos vive o encontro com o Outro, compartilhando vivências. Assim, o lugar é fundante para a nossa experiência de ser-e-estar-no-mundo.

\section{A Vila de Provetá}

Onde fica a Vila de Provetá? Ela integra a Ilha Grande, que faz parte do Município de Angra dos Reis, no sul do Estado do Rio de Janeiro - vide Fig. 1. Angra dos Reis é conhecida internacionalmente pelas suas belas paisagens e vocaçáo turística, sendo as suas praias uma das suas principais atraçôes.

Fig. 1 - Localização da Vila de Provetá, Ilha Grande, RJ

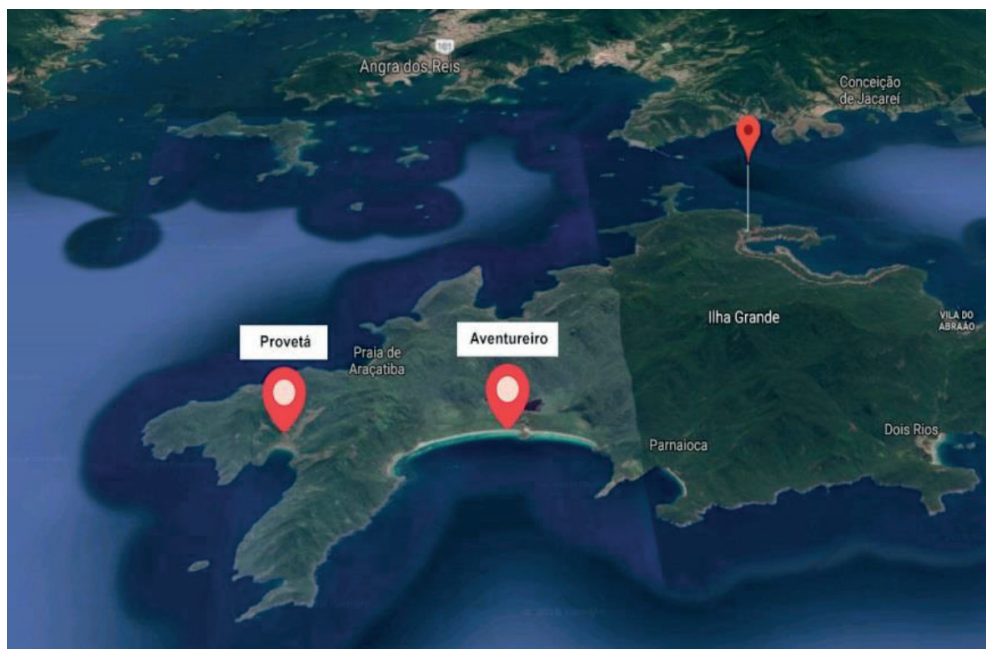

Fonte: Google Maps 2020 (Editado pelos autores) 
Não diferente das demais localidades, Provetá possui belas praias, Fig. 2, porém, como abordaremos, o uso delas sofre uma forte influência pelo modo de ser religioso dos sujeitos que lá habitam. A Vila possui o segundo maior quantitativo populacional da Ilha Grande, com aproximadamente 1500 moradores, sendo o turismo a principal atividade econômica.

Dos 1500 habitantes de Provetá, $80 \%$ se consideram cristãos protestantes. Mas o que isso significa? Significa que havia e há outras designaçóes culturais e religiosas que não a cristã protestante na comunidade. Primeiramente, é importante termos em mente que Provetá se trata de uma comunidade de pescadores caiçaras, ou seja, sua história remonta uma origem indígena. Já no início do século passado, tínhamos a maioria de seus habitantes como católicos $\mathrm{e}$, nas últimas décadas, como cristãos protestantes. $\mathrm{O}$ intrigante é que todos eles são vinculados a uma única denominação, a Assembleia de Deus. Assim, é justamente o modo de ser adotado pelos adeptos dessa denominaçáo, especificamente nessa localidade, que norteia o cotidiano dos provetaenses. Em outras palavras, aqueles que não são cristãos protestantes se adequam a normas e hábitos dos primeiros.

Com isso, lançamos duas questóes para nortear a discussão: 1) Como ocorreu a chegada das primeiras pessoas que contribuíram para a implantação do templo da denominação na Vila? e 2) Quais as estratégias utilizadas pelos líderes protestantes que conduziram e influenciaram a vivência dos habitantes de Provetá ao ponto de determinarem o que pode ser feito ou não no dia a dia dessa localidade?

Fig. 2 - Vila de Provetá, vista do Alto do Aventureiro

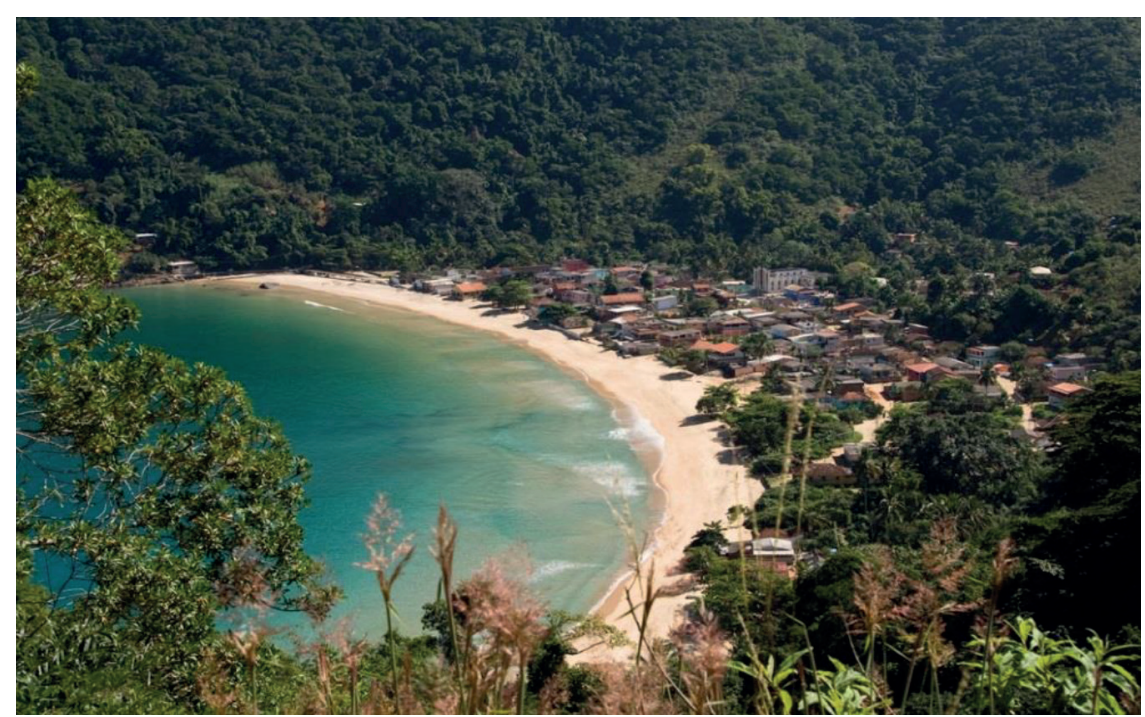

Fonte: Arquivo pessoal de Felipe Maia, 2018. 


\section{As missóes Evangélicas na Vila de Provetá}

Antes de nos atermos especificamente às missóes evangélicas na Vila de Provetá, cabe contextualizar como estas ocorreram no Brasil, em específico, aquelas empreendidas pela Assembleia de Deus.

A Assembleia de Deus possui, como seus fundadores no Brasil, os missionários suecos Adolf Gunnar Vingren (1879-1933) e Daniel Gustav Högberg (1884-1963), este conhecido como Daniel Berg. O primeiro templo em terras brasileiras foi erguido em 1910, na cidade de Belém, no Estado do Pará (FAJARDO, 2015; VINGREN, 2007).

Com o intuito de disseminar o protestantismo no país, diversos missionários se espalharam pelo Brasil, objetivando evangelizar a população. Assim, em 1923, a Assembleia de Deus aportou na cidade do Rio de Janeiro, fato que contribuiu para que Vingren e sua família viessem a residir na capital federal daquela época, segundo Emílio Conde (2008).

O protestantismo em terras fluminenses rapidamente se popularizou, principalmente, nas camadas mais pobres da população. Dentre as diversas pessoas que foram evangelizadas, estavam os provetaenses Deoclesio Neves e a sua esposa, Helena, responsáveis por introduzirem os preceitos da denominação Assembleia de Deus na Vila de Provetá.

Desse modo, a comunidade de Provetá teve o contato e a inserção da religiosidade cristã protestante de modo não muito diferente de boa parte das missóes evangélicas empreendias pela Assembleia de Deus, para se estabelecer no Brasil, a não ser pelo mito que se criou quanto à chegada dos missionários na Vila, em 1935. Segundo relatos, uma viagem que duraria aproximadamente 1 hora de barco durou 4 horas, em péssimas condições de navegabilidade e sob um calor escaldante, fato que colocou em riscos os tripulantes da embarcação. Por meio de depoimentos, se relata que, após Deoclesio realizar uma oração, uma nuvem se interpôs entre eles e o Sol, protegendo-os até atracarem na Vila. Esse acontecimento fortaleceu a imagem de Deoclesio como um líder carismático, que enfrentou dificuldades para levar a "mensagem divina” aos não adeptos do protestantismo cristão que residiam na Vila.

Apesar de haver variação dos relatos referentes ao casal de missionários que retornavam a Provetá, esses se convergem no seguinte ponto: a chegada deles contribuiu para a mudança de como as pessoas viviam, bem como da religião professada pela maioria da população, que era o catolicismo romano. Os provetaenses mais antigos que entrevistamos afirmaram que a Vila, antes da chegada do protestantismo, "era um lugar doente" e que "a maioria da populaçâo jazia de lepra", mas, por outro lado, "após a chegada dos missionários, a prosperidade chegou para seus habitantes".

Cabe ressaltar aqui uma certa contradição entre os preceitos ortodoxos, que caracterizam a Assembleia de Deus como uma denominação protestante pentecostal, e a vinculação de acontecimentos divinos a um sujeito. Isso foge aos ensinamentos tradicionais do protestantismo, provenientes de Martin Lutero, que não atribui milagres a um sujeito, e sim, entende que há 
uma providência divina ${ }^{4}$. De toda maneira, qual a importância desses relatos e do mito? Como eles influenciaram no modo de ser e na lugaridade dos sujeitos em Provetá?

\section{A consolidaçáo da Assembleia na Vila}

Essas repentinas melhoras na Vila foram associadas à chegada de Deoclesio e sua esposa, que foram preponderantes para que as suas ideias viessem a prosperar entre os habitantes da comunidade. Ainda buscando a compreensão dessa expansão da influência do missionário sobre os provetaenses, a cura de origem divina e as intervençóes públicas por meio da construção de equipamentos públicos facilitaram a sua estratégia para consolidar a presença cristá protestante em Provetá.

Com isso, o propósito inicial de uma disputa com qualquer outro tipo de matriz religiosa professada por algum morador da Vila foi facilmente vencido pela Assembleia de Deus, representada na figura de Deoclesio. A cada disputa vencida, havia a manutenção do seu pensamento religioso e o estabelecimento de parâmetros morais e de costume, fatores estes que contribuíram para a instituição e preservação de uma territorialidade religiosa por parte de Deoclesio, na Vila de Provetá.

Rosendahl $(2002 ; 2010)$ destaca que a existência de uma dada religião contribui para a criação de um dado território e, no contexto do mesmo, ocorrem diversas açóes religiosas individuais e coletivas. Porém, para a manutenção dessa territorialidade, é necessária a adoção de diversas estratégias político-espaciais. Pode-se considerar a existência da territorialidade religiosa que significa o conjunto de práticas desenvolvidas por instituiçóes ou grupos, no sentido de controlarem uma dada localidade (ROSENDAHL, 2002; 2010). Tal territorialidade contribui para que a religião possua uma dimensão política e econômica, influenciando a dinâmica social e as transformaçóes no modo de ser dos sujeitos em seus cotidianos e, consequentemente, a maneira como se relacionam com o lugar onde habitam.

Nessa perspectiva, podemos considerar o território como sendo vivido e experienciado pelo ser-no-mundo, considerando as intencionalidades no lugar, que, por sua vez, possui uma importância ímpar, pois é no lugar onde o modo de ser se vela e se revela. Esse movimento contribui para que ele seja dotado de dinamismo, porque as experiências vivenciadas não se revelam de forma estática (BERNARDES; AGUIAR, 2020). Em Provetá, o modo de vida religioso contribui para des-velar a lugaridade, entendendo esta como a relação dos seres em movimento com os lugares, de forma situada, como seres-em-situação (MARANDOLA JR., 2012; SARAMAGO, 2008).

A excentricidade que é ligada à imagem da Assembleia de Deus e de seus adeptos em Provetá, desde a sua implantação na Vila, fazem com que as práticas realizadas venham a diferir

\footnotetext{
4 Fato atualmente esquecido ou ignorado por uma parcela considerável de denominaçóes protestantes que vinculam a sua imagem a de um líder carismático, conforme explicita Max Webber (1964; 2006).
} 
de outras localidades onde há a atuação de missionários ligados ao protestantismo cristão. Um exemplo da atuação dos membros da denominação em Provetá é destacado por Maia (2020, p. 48):

[...] entre as várias marcas do pentecostalismo, impressos na Assembleia de Deus [em Provetá], uma que se destaca é o rechaçamento da cultura local, o movimento em Provetá incorporou a vivência caiçara ao pentecostalismo, trazendo vida a seu discurso bíblico. Dessa forma, a transformação religiosa alavancou a mudança de elementos culturais $[. .$.$] criando uma nova identidade cultural.$

Pelas palavras de Maia, é possível notarmos que houve a ressignificação cultural, caiçara e católica, utilizando-se, como parâmetro, o pentecostalismo da Assembleia de Deus. Todavia, não se tratou somente da ressignificação das normas e dos costumes existentes na Vila, já que houve a mudança do padrão arquitetônico da localidade, uma vez que as obras passaram a ser construídas voltadas para o templo da Assembleia de Deus, vide Fig. 3. Ainda, as festividades e feriados religiosos católicos foram banidos do calendário da localidade e passaram a vigorar aqueles instituídos pela liderança da Assembleia de Deus. O banimento partiu do argumento de que tais eventos não representavam a "veracidade das datas históricas", como afirmou um dos religiosos que entrevistamos.

\section{Fig. 3 - Assembleia de Deus em Provetá e a praça central da Vila}

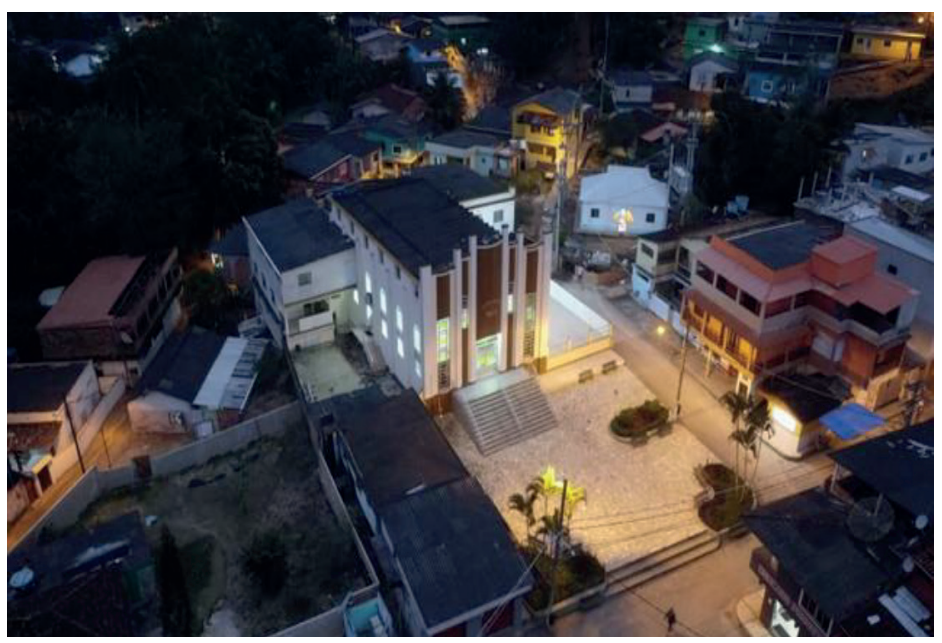

Fonte: RJ.OLX.COM.BR, 2020.

Dessa maneira, o protestantismo cristão e a consolidação da Assembleia de Deus na Vila mudaram o cotidiano da comunidade. O líder religioso, o pastor da denominaçáo, passou a ter poder nas mais diversas esferas sociais da Vila. Mas uma das principiais influências em relaçáo aos sujeitos da comunidade ainda se faz pela autoridade de aplicar a Bíblia ao contexto local (MAIA, 2020, p. 50). Mediante esses fatos, se passou a convencionar o provetaense como um "ser assembleiano" ou "de dentro", como explicitou Birman (2006).

Considerando-se todo esse contexto, retomamos algumas questóes: como vivem na comunidade aqueles que não compartilham o protestantismo? Existe esse Outro, que busca 
vivenciar a sua lugaridade de forma distinta da maioria dos sujeitos protestantes da Vila? Mesmo considerando que respondemos em parte essas questóes, cabe-nos retomá-las com maior profundidade.

\section{O Outro e o Assembleiano na Vila}

Como já citamos, um discurso que possui força em Provetá é a máxima do "ser assembleiano", principalmente, nas cerimônias realizadas pelos líderes da Assembleia de Deus.

Maia (2020, p. 51), refletindo sobre o "ser assembleiano", nos indica que uma imagem representativa nas ruas da Vila são os homens trajando paletó e gravata e as mulheres com suas saias e vestidos longos, como segue:

Em Provetá, as mulheres evangélicas usam saias ou vestidos com manga e os homens, calça comprida e camisa de manga. Nelas também é observado o não uso de maquiagens ou joias. O cabelo é questáo sagrada para a Assembleia de Deus em Provetá, considerado o véu natural, por isso os mesmos devem ser longos e compridos. Para o banho de mar, as mulheres tomam banho trajadas como no cotidiano, e os homens também, se utilizando de uma bermuda, mas mantendo a camisa sobre o corpo. Essa característica conferiu à Provetá o título de única praia da Ilha Grande onde se toma banho "de roupa".

O estabelecimento de normas de como se deve agir no cotidiano náo se restringe aos membros da Assembleia de Deus, elas são extensivas a todos os habitantes da Vila, impondo, de certa maneira, um modo de vida ao Outro que não é evangélico, o qual podemos entender de duas maneiras: o Outro próximo, que é o provetaense, e o Outro distante, que seria o turista, o habitante de uma outra localidade que não comunga os preceitos estabelecidos pela Assembleia de Deus na comunidade. Uma consideração importante é que, mesmo que uma dada pessoa não seja oriunda ou habitante de Provetá, mas que seja protestante, ela passa a ser considerada como de dentro, pela sua identificação e ligação, pelo viés religioso, com os assembleianos da comunidade.

"Ser assembleiano" se tornou sinônimo de ser provetaense. Essa influência possui uma importância ímpar, tanto que, segundo relatos apresentados por Maia (2020) e Birman (2006), a data mais importante em Provetá passou a ser o aniversário de fundação da igreja. Isso é reforçado pelas afirmaçóes de alguns de seus habitantes, como: "foi um lugar que Deus escolheu para Ele"; os moradores de Provetá são "eleitos pela graça divina” (BIRMAN, 2006, p. 08; BAKKER, 2008, p. 123).

Essa maneira de agir e pensar tem um impacto profundo em Provetá, empiricamente, demonstrado pelo poder dos líderes religiosos, que buscam afastar os turistas que não concordam com as imposiçôes da Assembleia de Deus. Isso envolve a proibição do uso de sungas e biquínis nas praias, do uso de drogas e bebidas alcoólicas e da execução de músicas não evangélicas em locais próximos ao templo. 
Essa influência do modo de "ser assembleiano" sobre o lugar Provetá é fruto de uma construção que perpassa a fundação do templo e o reforço do culto à imagem do seu fundador e ao seu modo de viver, funcionando até como uma maneira de impor uma territorialidade religiosa. Além do exposto, uma consideração que corrobora essa estratégia é a alegação de que o pentecostalismo implantado em Provetá sacralizou a Vila, motivando a implementação de medidas para impedir a interferência profana. Essa sacralização do lugar é passível de alguns questionamentos, pois, se considerarmos, como Meslin (2014), que o sagrado apenas pode ser descrito por quem o vivencia, como essa sacralização afeta os que acreditam em um outro sentido religioso?

Como já mencionado, existe uma parcela de seus habitantes que não são protestantes cristãos e os Outros que não concordam com o estipulado pelos líderes religiosos. Boa parte desses Outros respeitam as normas e os costumes estabelecidos pela Assembleia de Deus por respeito ou pela proximidade parental que existe entre os habitantes da Vila.

Esses Outros são quase que esquecidos ou mesmo negligenciados pelos cristãos protestantes, como podemos constatar pelo depoimento de um pesquisador provetaense: " $E$ visto como normal para um membro que, ao crescer em um ambiente que o discurso de santidade norteia a sua caminhada religiosa, o lugar do Outro só é pensado, como no meu caso, ao encabeçar uma pesquisa cientifica."

Esse depoimento apenas ilustra e reforça a negligência em relação ao Outro. Porém, existe uma desconexáo entre essa maneira de pensar e o que entendemos como experiência religiosa, pois, segundo Heidegger (2014), o fenômeno religioso, quando ocorre, se dá através das pessoas, a partir do Dasein, que é o ente que cada um de nós somos, que possui, em seu ser, a capacidade de questionar, compreender e ir ao encontro do Outro no mundo circundante, que é "como aquilo que nos vem ao encontro, ao qual pertencem não apenas as coisas materiais, mas também objetualidades, ideias, ciências, artes etc.”. (HEIDEGGER, 2014, p. 16).

Assim, o modo de ser do Dasein não ocorre sem o Outro, e esses se dão no mundo. Por isso, esse encontro é o modo de ser-no-mundo, que, determinado pelo ser-com, mostra que o Dasein contribui para que o mundo seja sempre mundo compartilhado, onde o viver ocorrerá sempre na convivência (HEIDEGGER, 2018).

Sendo assim, não ocorre a possibilidade de não considerar a existência desse Outro em Provetá, que vive fora da comunidade evangélica, que é confundida como sendo a imagem que compreende a todos que moram na Vila. Mesmo porque esse modo de "ser assembleiano", na prática, apesar de negligenciar esse Outro que não corrobora a sua maneira de pensar, em diversas situações no cotidiano, busca romper, quase que abruptamente, como já apresentado, com a individualidade do Outro. Essa imposição do modo de "ser assembleiano", nesse contexto, objetiva refletir-se num pensamento e apenas num modo de ser, buscando uma espécie de totalização da maneira de pensar e agir que todos devem compartilhar como a "única correta".

Essa conjuntura contribui para que a convivência entre os diferentes ocorra mediante tensionamentos, pois essa tentativa de impor um pensamento constitui um ferimento quase 
que letal à alteridade que cada um de nós possuímos. Compreendemos essa como uma forma de se colocar na posiçáo do Outro, respeitando a existência de cada individualidade, cultura e maneira de pensar (LIMA, 2019). Assim, Levinas (2020, p. 26), ao abordar essa questão, explicita que "[...] para que a alteridade se produza no ser", é necessário um "pensamento", “é preciso um Eu”.

Nesse sentido, os "de fora" criam situaçóes para "driblarem" esse pensar autoritário que se impóe no cotidiano. Segundo abordou Birman (2006), para os "de fora", o tempo do ritual do culto no templo demarca o fazer das suas atividades, como: a hora de a mocinha voltar para o culto, antes que a sua ausência seja notada, marca o início das festas em locais afastados do templo; nos bares, onde alguns, de forma "clandestina", se encontram em horários mais avançados. Vale a consideração de que, em Provetá, existem apenas três bares localizados no chamado Canto do Inferno, que é uma localidade situada a uma certa distância em relação ao considerado Centro da Vila, onde está o templo da Assembleia de Deus.

É no Canto do Inferno que os Outros, como, por exemplo, os pescadores jovens, desafiam a autoridade dos líderes religiosos da Assembleia de Deus. Ressalta-se que tal desafio, dificilmente, é realizado em plena luz do dia e nos arredores do templo, pois, apesar das imposiçôes dos líderes, o respeito em relação à religiosidade prepondera na Vila. Não que tal relação de respeito não deva preponderar, mas nos parece que ela é uma via de mão de única.

Apesar da sua pequena extensão territorial, a Vila de Provetá apresenta esse dinamismo da existência de diferentes modos de ser-no-mundo no cotidiano e no modo como as lugaridades são vividas, fato que apenas corrobora a importância do debate em relação à vivência e às lugaridades, pois, com o modo de ser-no-mundo, fazemos parte do acontecer cotidiano e este, necessariamente, ocorre no lugar, até porque, como coloca Saramago (2008), o "ser implica, inescapavelmente, estar ou pertencer a algum lugar, como somos sempre ser-ẩ”.

\section{Consideraçóes finais}

Pensar a religiáo e a sua influência no modo de vida cotidiano das pessoas é de uma importância ímpar para buscarmos compreender o contexto que predomina em diversas localidades espalhadas pelo país. Seja o segmento católico, protestante ou umbandista, eles possuem, através da personificação das suas lideranças, o poder de estabelecer modos de vivência, que se espraiam pelas diversas dimensóes que o sagrado alcança da nossa vivência, relembrando Rosendahl (2002; 2010), além de influenciarem nas dimensóes política, econômica e do lugar.

Provetá é um típico exemplo de como essas dimensôes são afetadas por uma dada ideia religiosa e como tal fato tende também para um dualismo relacionado ao modo de vida dos habitantes da comunidade. Os adeptos ou os de dentro têm a sensação de viverem em uma localidade abençoada e sacralizada pelo modo de "ser assembleiano", porém esse mesmo modo de ser afeta o cotidiano do Outro que não compartilha as ideias estabelecidas pela denominação 
local. Esse Outros, em diversos casos, é quase que obrigado a conviver com a imposição de um dado modo de vida, até mesmo sendo esquecido pelos de dentro, como apontam alguns relatos dos moradores, sejam adeptos ou não. Esse Outro, seja o próximo ou o distante, como abordado, acaba tendo que se contentar em viver quase que na penumbra do pós-culto, no chamado Canto do Inferno.

Para não finalizarmos, destacamos que este texto não possui o intuito de apontar culpados ou inocentes, e sim, trazer à luz uma discussão sobre como uma determinada maneira de pensar pode, de certa maneira, ofuscar o Outro, sendo que isso se torna uma verdadeira contradição, pois só nos reconhecemos como tal a partir do Outro, com o qual compartilhamos o nosso modo de ser e estar no mundo, inclusive, a própria lugaridade se dá através do compartilhar entre o Eu e o Outro (MARANDOLA, 2020).

Viver respeitando e reconhecendo a alteridade de cada pessoa é um dos caminhos possíveis para que haja um entendimento. Que, através desse entendimento, realmente o lugar seja para todos, onde cada qual possa se expressar sem ter que se submeter a um dado pensamento, que busca totalizar para si o direito de ser o único certo ou a verdade absoluta. Seja para o protestante ou o náo protestante, o mundo, para se constituir como tal, necessita da existência do Outro que pensa diferente, pois é o ser diferente que contribui para a beleza da diversidade, que traz à luz as lugaridades e os variados modos de ser-no-mundo.

\section{Referências}

BERNARDES, Antonio; AGUIAR, Felipe. O território como experiência: ensaio de Geografia Fenomenológica existencial. Caderno Prudentino de Geografia, n.42, v.2, p. 44-62, junho, 2020.

BIRMAN, Patrícia. O Espírito Santo, a mídia o território dos crentes. Ciências Sociais e da Religiáo, ano 8, n. 8,pp. 41-62, 2006.

BAKKER, André Werneck de Andrade. Deus, o diabo e a televisáo: mídia moderna de massa e pentecostalismo em uma comunidade evangélica da Ilha Grande. Dissertação. Programa de Pós-Graduação em Ciências Sociais da Universidade do Estado do Rio de Janeiro. Rio de Janeiro, 2008. 275 p.

CONDE, Emilio. História das Assembleias de Deus no Brasil. 6. ed. Rio de Janeiro: CPAD, 2008.

FAJARDO, Maxwell Pinheiro. Onde a luta se travar: a expansão das Assembleias de Deus no Brasil Urbano (1946 - 1980). Tese. Programa em História da Universidade Estadual de São Paulo. Assis. 2015. 358 p.

HEIDEGGER, Martin. Fenomenologia da vida religiosa. Trad. Enio Paulo Giachini/Jairo Ferrandin/Renato Kirchner. Petrópolis: Editora Vozes / Bragança Paulista: Editora Universitária São Francisco, 2014. 
HEIDEGGER, Martin. Ser e tempo. Trad. Marcia Sá Cavalcanti. Petrópolis: Editora Vozes / Bragança Paulista: Editora Universitária Sáo Francisco, 2018.

LEVINAS, Emmanuel. Totalidade e infinito. Lisboa: Ediçôes 70, 2020.

LIMA, Jamille da Silva. Identidade e lugar na metafenomenologia da alteridade Payayá. GeoTextos, n.2, v. 15, p. 13-33, 2019.

MAIA, Felipe Rodrigues de Almeida. Identidade cultural e religiosidade na Vila de Provetá, Angra dos Reis, RJ. Trabalho de Conclusão de Curso de Licenciatura em Geografia da Universidade Federal Fluminense. Angra dos Reis. 2020. 61 p.

MARANDOLA Jr, Eduardo; HOLZER, Werther; OLIVEIRA, Lívia. Acertar o texto qual o espaço do lugar? Geografia, epistemologia e fenomenologia. São Paulo: Editora Perspectiva S.A, 2012.

MESLIN, Michel. Fundamentos de Antropologia Religiosa. A experiência humana do divino. Petrópolis: Editora Vozes, 2014.

PACHECO JUNIOR, Nelson Cortes. Da capital às tabancas: a lugaridade entre os guineenses e os missionários protestantes em Guiné-Bissau. Dissertação (Mestrado em Geografia). Campos dos Goytacazes: Instituto de Ciências da Sociedade e Desenvolvimento Regional/Universidade Federal Fluminense, p.164. 2020.

ROSENDAHL, Zeny. Espaço e religiáo: uma abordagem geográfica. Rio de Janeiro: Ed. UERJ, 2002.

ROSENDAHL, Zeny. Espaço, cultura e religião. In: CORRÊA, Roberto Lobato; ROSENDAHL, Zeny. Introduçáo à Geografia cultural. Rio de Janeiro: Bertrand Brasil, 2010.

SARAMAGO, Ligia. A topologia do ser. Lugar, espaço e linguagem no pensamento de Martin Heidegger. Rio de Janeiro: Editora PUC-Rio; São Paulo: Loyola, 2008.

VINGREN, Ivar. O Diário do pioneiro: Gunnar Vingren. 13. ed. Rio de Janeiro: CPAD, 2007.

WEBER, M. Economía y sociedad. México / Buenos Aires: Fondo de Cultura Econômic, 1964.

WEBER, Max. A ética protestante e o "Espírito" do Capitalismo. 4. Reimp. São Paulo: Ed. Schwarcz LTDA, 2006. 